\title{
The Real Thinking and Countermeasures of College Physical Education Reform Under the Concept of "Full Person Education" in the New Period
}

\author{
Yang Liuqing \\ School of Art and Design, Heyuan Polytechnic, Heyuan, Guangdong, China \\ 69972640@qq.com
}

\begin{abstract}
In order to implement the requirements of the National Medium- and Long-Term Education Reform and Development Plan (2010-2020) for the reform of college physical education, through the literature and data method, we have found out that the current college physical education still exists. Students have serious physical crisis and classroom crisis. Therefore, it is necessary to reform and innovate college physical education from the perspective of enhancing the interactive sharing of college physical education classrooms, focusing on cultivating sports composite application talents, and establishing clear goals and reforming innovative teaching content. It is suggested that the reform of college physical education in the new era: 1 . Follow the concept of whole-person education and establish a sound security system; 2. Adhere to the innovation of physical education and establish a new mode of physical education; 3. Make full use of educational resources and strengthen the construction of teachers. Following the concept of "all-person education", we will construct a life community that blends and integrates "body" and "education". It not only pays attention to the cultivation of students' comprehensive ability, but also advocates the development model of whole people, and provides reference for the reform of college physical education in the new era.

Keywords: whole-person education, new era, physical education, school physical education, education reform, teaching innovation
\end{abstract}

\section{新时期基于 “全人教育”理念下高校体育教育改革的实 然之思与应然之策}

杨柳青

河源职业技术学院艺术与设计学院, 河源, 广东, 中国 69972640@qq.com

摘要: 为贯彻《国家中长期教育改革和发展规划纲要（2010-2020 年）》对高校体育教育改革的要求, 通过文献资料法对新时期高校体育教育改革梳理后发现，目前高校体育教育还存在学生身体危机和课 堂危机严重问题。因此应该从增强高校体育课堂的互动分享性、注重培养体育复合型的应用人才、树 立明确目标改革创新教学内容三个维度对高校体育教育进行改革创新。建议新时期高校体育教育改革: 1. 遵循全人教育理念，建立完善的保障制度；2. 坚持体育教育创新，确立体育教学新模式； 3 . 充分利 用教育资源，加强教师团队建设。遵循 “全人教育” 理念，建构 “体”与 “育” 相互交融与贯通的生 命共同体, 既注重学生综合能力培养, 又要倡导全人发展模式, 为新时期高校体育教育改革提供参考。 关键词: 全人教育, 新时期, 体育教育, 学校体育, 教育改革, 教学创新

1. 前言

随着时代变迁的发展，体育教育在高校教育中占有
着特殊的地位, 发挥着不可忽视的重要作用。诚然, 进入教育发展的新时期, 体育教育已经成为衡量学校 教育水平的重要指标之一, 国家大力提倡培养全能型 应用人才。高校是国家生产知识精英的主要阵地, 要 
想提升输出质量, 必须把好输入关。教育是对学生进行 知识、技能、心理、体育、德育、智育、美育等方面的 综合教育。随着大学生体质健康呈下滑趋势, 国家越来 越重视体育的教育。面对高校体育教育还存在学生身体 危机和课堂危机严重问题, 国家有关部门对新时期高校 体育提出新的挑战, 所以高校体育教育改革势在必行。 《国家中长期教育改革和发展规划纲要 (2010-2020 年)》 提出: “把改革创新作为教育发展的强大动力, 改革教 学内容、方法手段, 突出培养学生的自主能力和创新思 维。” 纲要还指出: “各高校可根据自己的实际情况制 定教学大纲, 充分利用自然资源和户外环境, 制定教学 目标, 自主选择教学内容, 有的放矢地进行教学改革和 试验。” ${ }^{[1]}$ 体育教育改革潮流势不可挡, 遵循 “全人教育” 理念，建构 “体育” 与 “教育” 相互交融与贯通的生命 共同体, “体教结合的宗旨在于协同与平衡, 以促进个 体的全面发展” ${ }^{[2]}$, 全面提高学生多综合能力素养, 以此 来建构符合学生需求的体育教育课程理论体系。

\section{2. 新时期高校体育教育改革的实然之思}

\section{1. “全人教育” 理念的植入}

“全人教育 (holistic education) 是 20 世纪 70 年代兴起于美国的一种带有强烈批判色彩的教育思想流 派。全人教育以联结、整体性和存在 3 个基本原则为基 础, 以了解学生心理需求、能力、经验、性格和意愿为 主观条件, 强调以学生心智及体魄等方面的健全均衡发 展为目标 ${ }^{[3]}$ ”。20 世纪末期, 全人教育理念已经风靡全 球, 很多国家先后付诸实施并取得丰硕成果。我国最先 开始在香港、台湾地区践行 “全人教育” 体系, 而后在 北京大学、清华大学和华中科技大学等高等学府开始正 式开设全人教育课程。尽管引进了先进的教育理念, 但 很多高校仍然固守陈旧的教学模式, 并没有真正在高校 中践行 “全人教育” 理念, 使得全人教育理念最终只能 成为一纸空文、空中楼阁, 导致结果谬之千里、差强人 意。高校体育教育, 必须符合当前人才培养需求的教育 理念。高校体育教育改革的实践过程, 是导入并践行现 代体育教育新理念的过程。高校体育教育改革, 围绕创 新与实效，在全人教育理念下实现 “体” 与 “育” 的完 美融合, 最终实现 “全人”培养模式。“贯彻 “全人教 育理念, , 培养学生综合素质能力的新型教育模式, 是 对学生 “体” 和 “育” 的全面教育, 能够充分发挥体育 在育人教育中的重要意义。既符合国务院和教育部的政 策导向, 又符合新时期高校对全面发展创新人才的培养 要求。” [4] 故而任何体育改革都必须坚持以学生为本, 最终实现全面发展的终极目标。高校体育教育改革符合 时代要求, 植入新型教育理念, 为高校教育提供科学 “育 人标准” 的同时, 也为学生个体植入了 “终身体育” 的 观念与习惯, 使得体育教育价值再提升。

\section{2. 高校学生身体危机}

在新媒体、大数据时代背景下，智能手机、网络 信息化的便捷性给大学生生活带来了史无前例的颠覆 性改变。譬如, 电子商务、网上购物、美食美团等强 势来袭，让愈来愈多的大学生更喜欢 “宅” 在寝室， 与电脑、手机、 IPAD 为伴, 更喜欢陶醉于网络虚拟世 界的快感, 懒得走出宿舍去呼吸新鲜空气, 懒得出去 尽情享受大自然赐予的阳关浴, 懒得去和老师、家人、 同学多沟通交流，更何谈奔向操场进行枯燥的身体锻 炼。据不完全统计, 现在高校学生亚健康人群基数越 来越庞大, 且人数每年呈递增趋势发展。我国现在正 处于从体育大国向体育强国转变的关键时期, 学生体 质这样持续下滑十年，后果真是不堪设想！“2015 年 11 月 25 日，国家体育总局发布《2014 年国民体质监 测公报》显示: 与 2010 年相比，大学生身体素质继续 呈现下降趋势 ”[5]。这样持续下降的数据不得不令人 深思，也给在体育一线工作的体育教师带来极大的困 扰。每年大学生体质测试中的 800 米和 1000 米都成了 高危项目, 学生晕倒、猝死事件屡屡发生, 使得大学 生体质测试数据陷入持续下降的恶性循环怪圈中, “少 年强则中国强”、“中国体育强国梦”口号, 在大学 校园也都将衍变成为一个伪命题。由是说, 新媒体时 代就好像是一把双刃剑, 在给人们生活带来舒适便利 的同时, 也残忍地剥夺了人们身体活动的机会。大学 生群体永远走在时代发展的最前沿, 无疑是这一社会 变化的最大群体之一, 学生身体危机亟需引起国家政 府高度重视。

\section{3. 高校体育课堂危机}

高校体育课堂危机直接影响体育教师的价值。近 年来, 高校体育课堂持续边缘化, 主要表现为学生身 体锻炼时间严重不足，没有时间的充分保障，谈何提 高学生身体素质。随着多媒体信息技术的飞速发展, 学生获取体育知识的路径变多, 无论是时效性抑或是 观赏性都大大增强, 极大地削弱了体育教师在体育课 堂的垄断地位。自新中国成立以来, 高校体育教育的 改革从未停歇, 学校体育的地位和功能在理论上从未 被撼动，但其实早已名存实亡。“近些年推崇的 “全 人教育” 思潮虽引发了高校体育对大学生身心发展的 讨论, 但是从大学生身体素质 30 年来持续下降的趋势 来看, 这些讨论仿佛是坐而论道。”[6] 究其缘由, 很 大程度上归因于高校体育文化及其制度保障的缺失。 高校体育教育改革, 将学生身体健康、心理健康与社 会法则作为改革的目标遵从，不断推进现代体育教育 模式的科学重构, 在目标定位、课程优化中体现教育 新要求、发展新趋势, 在适应社会对人才素质的个性 化要求的同时, 更切实推动学生体质健康化、心理健 康化、发展均衡化。 


\section{3. 新时期高校体育教育改革的应然之策}

\section{1. 增强高校体育课堂的互动分享性}

“高校体育课堂是大学生学习存在经验的过程, 是 师生追求主体性、经验分享的过程。” [7]在 “全人教育” 理念下, 以教师为主导, 学生为主体, 充分发挥教师的 科研优势, 在有限的时间和空间里, 既要向学生传授理 论知识和动作技能, 更重要的是帮助解答学生在体育实 践中遇到的疑惑问题, 最终实现师生课堂教与学的良性 互动与分享。在课堂互动分享过程中, 不只是在给学生 传授知识, 其实也是教师自我提升的过程, 最终达到教 学相长的效果。随着互联网技术的快速发展, 信息技术 的大作宣传和应用, 学生学习渠道不断拓宽, 自学能力 得到大幅度提升, 开放式、多元化教学方式备受学生的 青睐。衡量教学质量好坏的一个重要指标就是学生在课 堂参与的互动度和学习行为的表现形式。因此, 只有体 育教师主动参与课堂教学创新, 最大限度激发学生体质 潜能, 增强体育课堂的互动分享性, 才能保证高校体育 课堂改革落到实处。

\section{2. 注重培养体育复合型的应用人才}

随着中国社会经济突飞猛进的发展，根据人才市场 需求, 国家和政府对体育教育提出了新的挑战, 致使体 育就业岗位格局发生了巨变, 尤其在篮球、足球、田径 等运动项目上表现尤为突出。随着社会需求和就业岗位 的变化, 导致原来就业形势较好的 “一专多能” 型人才 (即要求具备一个专项多个辅项) 逐渐被岗位不固定的 “多能一专” 型人才 (即要求具备多种能力来服务一个 岗位) 所替代, 所以要求高校要从多方位改进体育教学方 式和体育教学内容。新时期高校体育教育教学都在不断 吐故纳新, 打破陈旧教育观念、超越习惯思维壁垒, 不 断冲击体育教师的知识价值观, 不断更迭高校体育教学 固有模式, 构建符合时代标准要求的体育教学授课新模 式。例如, 通过大力推进 “参与体验式教学模式和理论 课教学的翻转课堂教学模式等”, [8] 加强体育理论与实 践的相互交融, 使理论更好的为实践服务。以此来激发 学生学习兴趣, 挖掘学生运动潜能, 这既是在响应《国 家中长期教育改革和发展规划纲要（2010-2020 年）》政 策, 又是在努力推进体育教育改革创新, 注重培养体育 复合型的应用人才。

\section{3. 树立明确目标来改革创新教学内容}

面对目前高校师生体育观存在偏颇、学生体质健康 状况差、体育教学内容单调乏味和课外锻炼质量不高现 象, 高校应该树立明确目标来改革创新教学内容。根据 大学生不同的专业特点, 设置不同的具体教学目标, 而 且要改变之前传统的填鸭式、灌输式传教, 要让学生在
主动参与、实践与创新中学习。“《国家中长期教育 改革和发展规划纲要 ( 2010-2020 年)》明确提出：要 通过 “倡导启发式、探究式、讨论式、参与式教学, 帮助学生学会学习” [9]。可借鉴国外盛行的 “参与式 行学研”教学模式, 它最大限度地开发和利用了教学 资源。“参与式行学研教学模式旨在提供一个民主的、 开放式的、参与式的教学环境。它通过对学生学习行 为的干预, 进而提高学生的学习效果。”[10]培养学生 养成良好的思维习惯, 在学习中不断反思, 在反思中 不断学习, 进而整体提升个体间的团结与协作、表达 和反思等多种能力, 促进学生综合素质全面发展。

\section{4. 结论与建议}

\section{1. 遵循全人教育理念, 建立完善的保障制 度}

高校体育教育改革的推行, 是对传统体育教育“以 操场为中心” 观念的重新审视, 是适配当前人才素质 需求而做出的理念转向与思路破解。而体育教育改革 的价值就体现于学生这个主体素质是否得到最大化发 展提升上。故而, 体育改革必须围绕全人教育理念, 在体育教育趣味的培育、激发层面进行深度考量, 进 而让学生在体育之 “趣” 中吸引, 在体育之 “趣” 中 主动, 在体育之 “趣” 中成长。结合体育教学的特殊 性, 制定相应的管理制度。另外, 需要在教学改革中 建立相配套的教学管理机制、健全体育教育管理制度、 师生评价激励制度等。

\section{2. 坚持体育教育创新, 确立体育教学新模 式}

高校体育教育改革要扭转大学生对体育教学的传 统认识, 不能把体育课程仅仅看作是增强体质、愉悦 身心、掌握运动技能的途径, 更应该注意到体育教学 对培养立德树人起着至关重要的作用。体育教育改革 不只是革新创新理念, 更要将创新理念运动到实践教 学过程中去。以大学生就业和职业发展为出发点, 革 新并完善体育教育教学内容, 健全或重构体育教学新 模式。譬如, 可以通过开设一系列户外课程的学习, 让大学生在愉悦教学过程中不断提升自身的身体素 质、思想素质、德育素质和心理素质。确立体育教学 “全人培养” 新模式, 旨在强调回归体育教育本能, 提倡全人发展的现实意义。

\section{3. 充分利用教育资源, 加强教师团队建设}

充分挖掘并利用一切可行的校内和校外体育资 源, 包括地域优势和自然条件，同时也可借鉴兄弟院 
校先进的制度经验, 根据自身特点进行自我更新和自我 优化。高校体育教育改革的关键是教师, 面对体育教育 改革的多元化发展, 应加强教师团队建设, 鼓励教师不 断充电学习和继续深造, 拓宽自己的知识和技能学习, 以适应 “全人教育” 的理念, 培养全能型人才。此外, 学校可邀请体育教育知名专家、学者来校坐客, 参与学 校体育教育项目研究或重点课题破解。同时要大力引进 和吸纳有才之士, 带动我校师资团队的科研能力, 为学 校长远发展储备人才。

\section{REFERENCES}

[1] Wang, L., He, S.Q., Zhang, H.F. (2005) Physical Education Curriculum in Colleges and Universities -- A Study on outdoor Sports Teaching System. Journal of Beijing sport university, 28(9):1159.

[2] Zhang, F., Yan, Z.L. (2012) Practical Thoughts and Appropriate Strategies for the Development of Chinese University Sports Think tanks. Journal of Physical Education, 25(03):32-37.

[3] Wang, L., He, S.Q., Zhang, H.F. (2005) Physical Education Curriculum in Colleges and Universities -- A Study on outdoor Sports Teaching System. Journal of Beijing sport university, 28 (9):1159.

[4] Liu, Y. (2016) Exploration of innovative training mode of public physical education in colleges and universities under the concept of "whole-person education". Journal of capital institute of physical education, 28(04):323-327.

[5] General Administration of Sport of China. Bulletin of National Physique Monitoring in 2014. 2015-11.

[6] Xie, D.X. (2016) Physical crisis and classroom crisis of college physical education. Journal of physical education, 23(06):82-86.

[7] Yin, X.L. (2012) Policy Research on University Physical Education Courses since the Reform and Opening up. Changsha: Hunan Normal University.

[8] Peng, Q.W., Wang, C.Y. (2012) Research on talent Training Reform of Local Application-oriented Colleges and Universities based on Lifelong Sports Service -- A Case Study of Huaihua University. Journal of Physical Education, 25(04):105-109.

[9] Sun, C.L., Yang, J.R. (2017) Exploration on the reform of theoretical course teaching mode for PE majors in colleges and universities. Journal of Shenyang institute of physical education, 36(05):88-96.

[10] Fariasa, C. Hastie P.A., Mesquita, I. (2015) Towards a more equitable and inclusive learning environment in Sport
Education: results of an action research-based intervention. Sport Education and Society, (7):1-16. 